\title{
Fiber from fruit pomace: A review of applications in cereal-based products
}

\section{Amparo Quiles, Grant M. Campbell, Susanne Struck, Harald Rohm \& Isabel Hernando}

To cite this article: Amparo Quiles, Grant M. Campbell, Susanne Struck, Harald Rohm \& Isabel Hernando (2016): Fiber from fruit pomace: A review of applications in cereal-based products, Food Reviews International, DOI: 10.1080/87559129.2016.1261299

To link to this article: http://dx.doi.org/10.1080/87559129.2016.1261299

Accepted author version posted online: 21

Nov 2016.

Submit your article to this journal

Џll Article views: 11

View related articles $\asymp$

View Crossmark data $\nearrow$ 
Application of fruit pomace in cereal-based products

Fiber from fruit pomace: A review of applications in cereal-based

\section{products}

Amparo Quiles ${ }^{a}$, Grant M. Campbell ${ }^{b}$, Susanne Struck ${ }^{c}$, Harald Rohm ${ }^{c}$ and Isabel Hernando ${ }^{a}$

${ }^{a}$ Grupo de Microestructura y Química de Alimentos, Departamento de Tecnología de Alimentos, Universitat Politècnica de Valencia, Camino de Vera s/n, 46022, Valencia, Spain.

${ }^{b}$ School of Applied Sciences, University of Huddersfield, Queensgate, Huddersfield, HD1 3DH, UK.

${ }^{\mathrm{C}}$ Chair of Food Engineering, Technische Universität Dresden, 01069 Dresden, Germany.

*Corresponding author.E-mail address: mihernan@tal.upv.es (I. Hernando)

\section{Abstract}

Fruit pomace is a by-product of the fruit processing industry composed of cell wall compounds, stems and seeds of the fruit; after washing, drying and milling, a material high in fiber and bioactive compounds is obtained. In bakery products, dried fruit pomace can be added to replace flour, sugar or fat and thus reduce energy load while enhancing fiber and antioxidant contents. The high fiber content of fruit pomace, however, results in techno-functional interactions that affect physicochemical and sensory properties. In this paper, different sources of fruit pomace are discussed along with their application in bread, brittle and soft bakery products, and extrudates. 


\section{Keywords}

bread; healthy bakery products; aerated structure; consumer acceptability

\section{Introduction}

Fiber from sources other than wheat can be added to cereal-based baked or extruded product formulations to confer particular nutritional or sensory properties. The fiber may come from many sources including barley, oats, rice, soy, sugar beet and pea ${ }^{(1 ; 2)}$. Their chemical and physical properties have some similarities with those of wheat fiber, and they all tend to have high water-absorption capacities so that additional water is required in the formulations in which they are applied. Another important source of fiber can be fruit pomace, as an alternative to its traditional use as for example animal feed or in composting ${ }^{(3)}$. When using fruit pomace fiber in cereal baked product formulations, it is important to consider that it contains a high amount of soluble dietary fiber (SDF) whereas, in cereal fiber, the fraction of insoluble dietary fiber (IDF) is higher ${ }^{(4)}$. Moreover, fruit dietary fiber (DF) concentrates generally exhibit a better nutritional quality than those from cereals because of the presence of significant amounts of associated bioactive compounds (flavonoids, carotenoids, etc.) and their balanced composition (higher fiber content, IDF:SDF ratio, water and oil binding capacity, lower energy, and phytic acid content) ${ }^{(5)}$.

\section{Dietary fiber in fruit pomace}

Different definitions of dietary fiber have been proposed in recent years. In 2009, an agreed definition was published $^{(6)}$ : DF means carbohydrate polymers with ten or more monomeric 
units, which are not hydrolyzed in the small intestine of humans, and which belong to the following categories:

- Edible carbohydrate polymers naturally occurring in the food as consumed;

- Carbohydrate polymers obtained from food raw material by physical, enzymatic or chemical means that have been shown to exhibit beneficial health effects as demonstrated by generally accepted scientific evidence to authorities; and

- Synthetic carbohydrate polymers that have also been shown to exhibit beneficial health effects.

Based on chemical, physical and functional properties, dietary fiber can be classified into soluble and insoluble DF. SDF includes pectins, gums, inulin-type fructans and some hemicelluloses, which dissolve in water by forming viscous gels. They are resistant to digestion in the small intestine but easily fermented by the microbiota of the large intestine. The fermentation of IDF, including lignin, cellulose and some hemicelluloses, is however severely limited in the human gastrointestinal tract ${ }^{(7)}$. SDF is considered to have benefits on serum lipids, while IDF is linked to laxation benefits. In addition, many fiber sources such as oat bran and psyllium are mostly soluble but still elevate stool weight ${ }^{(8)}$.

Despite a recommended fiber intake for adults of $25 \mathrm{~g} / \mathrm{d}$ (EFSA, 2010), most commonly consumed foods are low in DF; higher fiber contents are found in foods such as whole grain cereals, legumes and dried fruits ${ }^{(8)}$. In this context, the addition of processed fruit pomace to food formulations should also be considered because it may provide additional health benefits (9), and because it enhances sustainability of the food supply chain, as pomace is a by-product that usually goes into waste ${ }^{(3)}$. 
Apple pomace fiber is considered as a potential food ingredient because of its wellbalanced proportion of IDF and SDF and the presence of bioactive compounds such as polyphenols, flavonoids and carotenes. Concentrates from apple pomace as such and after processing have been also evaluated for their functional properties ${ }^{(4)}$. Depending on apple variety, pomace fiber content varies from around $35.5 \mathrm{~g} / 100 \mathrm{~g}$ dry matter (DM) in Golden Delicious to as high as $89.8 \mathrm{~g} / 100 \mathrm{~g}$ DM in Liberty ${ }^{(2 ; 4)}$. High amounts of phenolic compounds such as catechins and flavonol glycosides have been found in Golden Delicious, Red Delicious, and Granny Smith varieties ${ }^{(4)}$.

By-products from orange juice extraction also have a high potential as DF sources; this material is rich in pectin. There is an increasing interest in pectin because of its potential to lower blood cholesterol levels and triglycerides; pectin also affects glucose metabolism by lowering the glucose response curve. The main use of pectin is as a food additive because of its specific gelling properties ${ }^{(10)}$. Total DF content has been determined in different types of citrus fruits. Some orange varieties such as Valencia have substantial DF contents (64.3 g/100 g DM) (2), while others have lower contents as is the case for Navel, Salustiana and Valencia Late (35.4$36.9 \mathrm{~g} / 100 \mathrm{~g} \mathrm{DM})^{(10)}$. Fiber content in pomace from lemon varieties has been determined by Figuerola et al. ${ }^{(2)}$ : Fino 49 had the highest amount of total DF $(68.3 \mathrm{~g} / 100 \mathrm{~g} \mathrm{DM})$, with $90.8 \%$ of this being insoluble, while Eureka lemon had lower values of DF (60.1 g/100 g DM) with an IDF:SDF ratio of 5.5:1. Another citrus fruit pomace that has been proposed as a valuable DF source is grapefruit with $61.8 \mathrm{~g} / 100 \mathrm{~g} \mathrm{DM}^{(11)}$; the IDF:SDF ratio can also vary, being e.g. 12.7:1 for Ruby, and 5.9:1 for the Marsh cultivar ${ }^{(2)}$. Grapefruit fiber has also exhibited a high binding capacity to cholesterol compared to other citrus fibers ${ }^{(11)}$. Different tangerine varieties have 
also been proposed as good alternatives to cereal fiber for supplementation in foods ${ }^{(12)}$. Grape pomace fiber is a rich source of bioactive compounds such as phenolic compounds, polysaccharides, fatty acids and others ${ }^{(13)}$. Factors such as variety, culture characteristics or wine-processing procedures (i.e., time of contact between pomace and grape must during fermentation) may influence grape pomace fiber composition. Usual ranges of DF in these products are 50-75 g/100 $\mathrm{g} \mathrm{DM}^{(5)}$. Grape skins are important for the food industry as fiber-rich ingredient; Bravo and Saura-Calixto ${ }^{(14)}$ characterized grape skins from red and white varieties and found a DF content of 54.2 and $59.0 \mathrm{~g} / 100 \mathrm{~g}$ DM in red and white skins, respectively. Although data about SDF and IDF content of grape pomace vary, there is no doubt that grape pomace fiber is low in solubility. Owing to the large quantity generated from worldwide wine and grape juice production, grape pomace has the potential to serve as an important IDF source for functional food development ${ }^{(15)}$.

Peach DF concentrate obtained by drying the washed peach bagasse remaining after peach juice extraction was characterized by Grigelmo-Miguel and Martín-Belloso ${ }^{(10)}$. Total DF constituted 30.7-36.1 g/100 g of the peach DF concentrate. IDF was the major fraction in the product, but the high presence of soluble fraction (11-12 g/100 g DM) in comparison to cereal DF is noteworthy.

Plum pomace fiber has considerable amounts of DF, up to $64.5 \mathrm{~g} / 100 \mathrm{~g} \mathrm{DM}^{(16)}$. The fiber content depends on cultivar and on pomace processing as Milala et al. ${ }^{(16)}$ found when drying plum pomace with different methods such as air drying or freeze-drying (values of total DF from 38-49 g/100 g); they also found important contents of polyphenols as hydroxycinamic acids, quercetin glycosides and anthocyans in the different plum cultivars. Tropical fruits have been 
considered as DF source as well. Guava bagasse contains $37.7 \mathrm{~g} / 100 \mathrm{~g}$ DM total DF ${ }^{(17)}$, while mango peel contains high amounts (up to $28.1 \mathrm{~g} / 100 \mathrm{~g}$ ) of SDF and a high amount of polyphenols (up to $70 \mathrm{~g} / \mathrm{kg}$ ) ${ }^{(18)}$. Kiwi and pear pomaces were studied for composition and utilization as sugar and DF source by Martín- Cabrejas et al. ${ }^{(19)}$. Berries are considered an emerging source of fruit pomace; they contain high amounts of polyphenols, which remain in the pomace after juice extraction and promote health advantages ${ }^{(9 ; 20)}$.

\section{Application of fruit pomace fiber in bread}

The distinctive appeal of most cereal-based foods derives from their aerated structure, and none more than bread, the archetypal aerated food and grandfather of all aerated foods

${ }^{(21)}$. The problem with incorporating DF into bread is that it is generally detrimental to the creation of the aerated structure, diminishing the appeal of the bread and restricting the benefits to be obtained through consumption of the fiber ${ }^{(22)}$. Studies into the effects of fiber in baked goods have revolved around several themes, with most of the emphasis on cereal brans, particularly wheat bran; this work is instructive for considerations of effects of fruit pomace fibers.

Van der Kamp ${ }^{(23)}$, reporting on the Dietary Fibre 2003 conference, advised that "the development of products that are attractive to consumers and underpinning research to this end is a key element in efforts to increase the intake of dietary fibre". In the case of bread, the key to producing fiber-rich products that are attractive to consumers is softness. Cauvain et al. ${ }^{(24)}$ noted "there are sections of the community who find the density and coarse texture of traditional wholemeal bread unacceptable and would prefer to increase their fibre intake by consuming bread with the large volume and soft crumb characteristics of white bread." 
Collins ${ }^{(25)}$ noted that many consumers equate the firmness of dense brown and wholemeal breads with staleness, and advises that to produce such a bread so that it will sell "the key lies in making it feel soft and that is most successfully achieved by increasing the specific volume close to white bread values."

Much early work on the incorporation of fiber in bread concentrated on providing bakers with urgently needed practical guidelines for the production of acceptable wholemeal or high fiber breads ${ }^{(26 ; 25 ; 27-35)}$. Alongside this, a prominent theme has been understanding the mechanisms by which bran and other fibers have their deleterious effects. The most obvious effect is dilution of the gluten protein when a proportion of white flour is replaced with bran. This mechanism was first stated by Shetlar and Lyman ${ }^{(36)}$; however, they demonstrated that gluten dilution was not the only contributing effect, and subsequent studies have established that loaf volume decrease is greater than would be expected from dilution of the gluten alone $(37-39 ; 30 ; 31 ; 40 ; 34 ; 35)$

Secondly, bran particles are conceived to have a mechanical effect that physically disrupts gluten films, either during their formation in the mixer or when they are stretched into thin lamellae during the later stages of proving and early stages of baking $(28 ; 39 ; 41 ; 40 ; 36 ; 42 ; 43)$. This postulation led Shetlar and Lyman ${ }^{(36)}$ to propose fine grinding of the bran to minimize this mechanical effect, a strategy that proved successful, although possibly for reasons in addition to the mechanical effectiveness of the smaller particles, such as their increased rate of hydration. Studies of other DF sources have similarly found that particle size has a major effect on the fiber performance in breadmaking.

The possibility that bran decreases loaf volumes by reducing gas production has been 
firmly negated, with decreased gas retention clearly established as the reason for lowered loaf volumes $^{(40 ; 34 ; 44)}$. Gluten dilution and physical disruption by bran particles contribute to this reduced gas retention, along with an assembly of additional contributing factors. The interaction of bran with water is a major focus. Bran absorbs water, reducing its availability for film formation, and thus increases the optimum level of water required in the dough formulation ${ }^{(45 ; 46 ; 37 ; 47 ; 30 ; 40 ; 48 ; 43)}$. However, it absorbs this water only slowly, and at a rate and extent that depends on its composition and particle size ${ }^{(49 ; 50 ; 37 ; 51-54)}$. This slow hydration causes a lengthening of dough mixing times, while prehydration of the bran removes the increase in mixing times and increases the optimum water level still further ${ }^{(37 ; 44)}$. This additional water is retained by the loaf during baking, giving a heavier loaf and a lower specific volume $^{(55 ; 22 ; 37 ; 56)}$. Dreese and Hoseney ${ }^{(37)}$ and Rogers and Hoseney ${ }^{(34)}$, based on measurements of dough height during baking in an electrical resistance oven, argue that this water is also available for starch gelatinization during baking, thereby lowering the starch gelatinization temperature and, as a result, the extent of gas retention during baking (oven spring). This mechanism, if predominant, would imply that ultimately the effect of bran on gas retention is principally during baking, rather than earlier in the breadmaking process.

Thus, the three major mechanisms by which bran damages the aerated structure of bread are gluten dilution, physical disruption of gluten films, and competition for water (causing inadequate water availability for gluten film formation or, if extra water is added to compensate, increased water availability for starch gelatinization and the consequent reduction in setting temperature and reduced oven spring). Sivam et al. ${ }^{(57)}$, reviewing effects of added fiber in bread, similarly list for various noncereal fibers negative effects including reduced loaf 
volume, increased crumb firmness and darkened appearance, and conclude that "the two mechanisms causing reduced loaf volume are the dilution of gluten, and the interactions among fibre components, water and gluten" - essentially the same mechanisms as for cereal bran, although the higher soluble fiber content of some fruit pomace fibres compared with cereal brans will modify the nature and extent of these effects.

Another major theme has been evaluation and comparison of the breadmaking performance of alternative sources of dietary fiber, including (the following list is representative but not exhaustive): wheat bran fractions and extracts, oat bran and hulls, rye bran, corn bran, barley bran and flour, brewer's spent grains, triticale bran, soybean bran, coconut residue, hazelnut testa, field pea hulls, apple pomace, pear pomace, orange pomace, lemon pomace, grape pomace, date pomace, sugar beet fiber, chicory roots, potato peel and microcrystalline cellulose $(58 ; 59 ; 45 ; 46 ; 37 ; 60 ; 52 ; 53 ; 61-64 ; 33 ; 40 ; 65 ; 66 ; 35 ; 44 ; 67)$. In the context of the current review, a notable omission is work on berry pomace. In general, these studies demonstrate that the fiber under study has similar deleterious effects to cereal brans, and conclude that they can be incorporated at some level while maintaining acceptable bread quality. One can reasonably speculate that berry pomace studies will follow similar routes, attempting to minimize deleterious effects through sourcing or pretreatment, and concluding that acceptable products can be obtained up to certain levels of incorporation.

Bran tends to be deleterious to highly aerated baked goods, of which bread is the prime example and therefore possibly not the ideal vehicle for delivering bran into the diet ${ }^{(33)}$. As discussed elsewhere in this review, numerous workers have therefore studied the incorporation of bran and other fibers into other, less aerated, cereal-based goods including 
cakes, biscuits, muffins, breakfast cereals, snack foods and flat breads ${ }^{(68 ; 45 ; 33 ; 44 ; 69)}$.

The majority of studies are concerned primarily with wheat bran and wholemeal bread, and useful guidance for the likely effects of other DF sources including berry and other fruit pomace can be derived from these studies. The literature on this subject has some discrepancies, and different brans vary in the details and extent of effects; however, generally, addition of wheat bran increases dough water absorption and loaf weight, decreases dough strength, increases dough stickiness, decreases mixing and fermentation tolerances, reduces loaf volume and specific volume, coarsens crumb texture, darkens crumb colour, reduces crumb softness and can impart a bitter flavor $(70 ; 71 ; 55 ; 22 ; 25 ; 72 ; 37 ; 28 ; 38 ; 47 ; 39 ; 41 ; 56 ; 60 ; 30-32 ; 61 ; 73 ; 74 ; 40$; $54 ; 34 ; 36 ; 35 ; 42 ; 48 ; 43)$. The adverse effects are greater at higher levels of bran substitution.

Second only to wheat bran are studies on the incorporation of oat bran into bread. Krishnan et al. ${ }^{(52)}$ note that "The nutritive value of oats, their low cost, useful protein functionality, and desirable bland taste make oats a suitable supplement ingredient", while further interest in the production and consumption of oat bran was stimulated by the FDA's proposal to allow foods containing sufficient quantities of $\beta$-glucan to be labelled with health claims relating to heart disease ${ }^{(75)}$. Generally, at equal levels of addition, oat bran gives higher water absorption, stickier doughs and lower baked loaf volumes than wheat bran, but taste panellists tend to prefer the oat bran bread ${ }^{(46 ; 52 ; 44)}$.

With the rise of concerns about celiac disease and studies on gluten-free breads, a recent theme has been the incorporation of noncereal fiber sources into these breads ${ }^{(63 ; 64)}$. As noted above, the aerated structure of bread arises through the unique gluten proteins of wheat. It is these proteins that are problematic to sufferers of celiac disease, hence making 
production of gluten-free breads with acceptable aerated structures particularly challenging. The further damage to aeration contributed by DF makes the production of acceptable highfiber, gluten-free breads even more challenging, hence the recent focus on this subject. O'Shea et al. ${ }^{(63)}$ incorporated orange pomace into gluten-free bread formulations. They found, as with cereal brans, that the high water absorption capacity of fiber competes with starch for the available water, reducing starch granule swelling and decreasing batter viscosity and gelatinization rate. At a level of $5.5 \mathrm{~g}$ pomace per $100 \mathrm{~g}$ (rice flour + potato starch), the orange pomace bread was considered similar in sensory acceptability to the control, with a slightly less pleasant texture while chewing. Rocha Parra et al. ${ }^{(76)}$ incorporated apple pomace into a glutenfree bread formulation, noting that high levels of fiber gave less cohesive and resilient crumbs and lowered specific volume. Increasing water level served to counteract the negative effects of the pomace addition to some extent.

As noted above, compared with wheat and oat bran, studies on the incorporation of other fiber sources into bread formulations are sparse, and studies of berry pomace addition into bread appear to be absent. However, several patents relate to the use of wild berry, grape and apple or pear pomace in bread ${ }^{(77-80)}$, with claims around structure formation and higher yield due to the increased water binding capacity conferred by the fiber.

\section{Application of fruit pomace in sweet bakery products}

\subsection{Cakes and muffins enriched with fruit pomace fibre}

Sponge cake batters are complex systems in which air is incorporated into an oil in water emulsion ${ }^{(81)}$. Although they have a cellular structure similar to that of bread dough, there is limited, if any, gluten formation ${ }^{(82)}$. The cake batter usually consists of many ingredients 
including flour, sugar, egg, fat, leavening agents, salt, milk solids and water, and each of these has an important function in the batter. This has to be taken into account when adding DF, or when using DF to substitute flour, fat or sugar in this type of product. Table 1 shows the amount and type of fruit pomace that was used in different studies for these purposes. The main problems generated by incorporating fruit pomace fibre in a formulation come from detrimental effects of the fiber on the creation of the aerated structure, as is also the case for bread. The fruit pomace fiber has a high affinity for water, so the interaction of bran with water is one of major concerns related to this problem. In general, wheat flour substitution by DF decreases cake volume development, and because of the increased density, the texture of the final products becomes firmer, more gummy and less cohesive ${ }^{(83)}$. In fact, texture is the sensory attribute most influenced by the presence of fiber in cakes and muffins, A metaanalysis of sensory data ${ }^{(84)}$ showed that in the case of muffins, the texture acceptability was lowered when the muffin base acceptability was high.

\subsubsection{Fiber fortification}

Dried apple pomace was used by Wang and Thomas ${ }^{(85)}$ to substitute $50 \%$ of wheat bran in muffins. Products had a similar total DF content but, when conducting sensory experiments, the overall preference showed that they were significantly more desirable than the control bran muffins because of their softer texture. Masoodi et al. ${ }^{(86)}$ prepared cakes by adding 5,10 or $15 \%$ of apple pomace to wheat flour and observed acceptable physical properties of the cakes. Apple skin powder was used by Rupasinghe et al. ${ }^{(87)}$ to replace up to $32 \%$ of wheat flour in muffins, which resulted in a higher DF and total phenolic contents, and a higher total antioxidant capacity than in the control. 
Different methods for incorporating apple pomace in bakery products have been tested, and an improved method for preparing fiber-rich cakes was patented by Madhugiri et al ${ }^{(88)}$. Here, apple pomace powder (20-40\%) was converted into a gel-like substance that was part of the cake formulation. Muffins with mango pulp fiber were reported as nutritionally improved due to the retention of phenolic acids and carotenoids ${ }^{(89)}$. The addition of fiber-rich fruit pomace to soft bakery products can also be an alternative for people requiring a low glycemic response, as Romero-Lopez et al. ${ }^{(90)}$ demonstrated in muffins with DF from orange bagasse. Walker et al. ${ }^{(67)}$ prepared muffins with 5-10\% grape pomace; DF and total phenolic contents and radical scavenging activity were increased compared to the control formulation. The enrichment of muffins with $20 \%$ grape pomace ${ }^{(91)}$ enhanced their nutritive value without showing significant changes in the sensory profile. Aronia pomace powder was proposed to increase DF content in cakes and muffins, which also contained fresh Aronia berries or Aronia jam as fruit filling ${ }^{(79)}$. A similar procedure was given for different cakes using dried and milled apple and pear pomace to increase DF content, and to reduce energy load ${ }^{(78)}$.

\subsubsection{Use of fruit pomace fiber for fat substitution}

Fat substitution by fruit pomace results in major changes of cake structure and consequently of their physical properties, such as reduced volume and increased crumb firmness ${ }^{(92)}$. Fat functionality is highly versatile in baked products ${ }^{(93 ; 94)}$ : it not only helps in the incorporation of air bubbles into cake batter during mixing, it also contributes to emulsification. Fat further helps to leaven the product ${ }^{(95 ; 96)}$ and holds considerable amounts of liquid to increase and extend cake softness, and "shortens", that is, it interrupts the protein particles to break gluten continuity to tenderize the crumb ${ }^{(97)}$. Furthermore, the polar lipids stabilize the 
gas bubbles, thanks to their surface-active properties; they fill the gaps in proteinaceous films and consequently prevent the release of gas ${ }^{(98)}$. In reduced fat content products, the stability of air bubbles in the batter is lowered; they tend to coalesce and disappear, giving harder cakes ${ }^{(99)}$. Therefore, a prerequisite of fat replacers based on DF is that these are low in energy but sufficiently mimic techno-functional properties of fat ${ }^{(100)}$.

Fruit pomace-derived fibers used to replace fat in soft bakery products include, for example, peach DF where high-fiber muffins showed fiber contents of up to $10 \%^{(101 ; 10)}$. In the reduced fat and high-fiber muffins, moisture increased with DF content because of its high water-holding capacity. The addition of the peach DF darkened the muffins and increased their hardness. Muffins with peach DF up to $4-5 \%$ were considered as being similarly acceptable as the control by consumers. Melon skin and rinds were used by Al-Sayed and Ahmed ${ }^{(102)}$ to substitute wheat flour or fat in a cake formulation. The use of these materials retarded staling and reduced lipid oxidation during storage. Medium substitution levels ( $5 \%$ flour and $10 \%$ fat) produced acceptable cakes that were not significantly different from the control.

\subsubsection{Use of fruit pomace fiber for sugar replacement}

Sugar substitution by fruit pomace is challenging because of the important role that sugar plays in batters of soft bakery products. Sugar contributes to sponge cake characteristics by providing energy, sweetness, aroma and crust color formation via caramelization ${ }^{(103)}$, but also influences many technical and functional aspects. Sugar restricts gluten network development, and it raises starch gelatinization temperature ${ }^{(104)}$ and egg protein denaturation temperature ${ }^{(105)}$, causing a tenderizing effect on the final product texture. It also contributes to volume, as well as to humidification, which is linked to the sensory perception of a moist 
mouthfeel and tenderness. Sugar furthermore assists the formation of crystalline agglomerations of fat, thus improving air entrapment and air bubble stability during baking, giving rise to a more porous and spongy product.

When substituting sugar, it has to be taken into account that the main mechanism that destabilizes cake batter is gas diffusion from small to large bubbles. That is, a batter with more extreme variations in bubble size is less stable ${ }^{(81)}$. A sufficiently high batter viscosity decreases air mobility, which prevents bubble coalescence and improves the stability of the mixture ${ }^{(105)}$. When sugar is replaced by a sweetener, it is required that these functions are retained in the system, so fillers are needed to replace the bulk of sugar ${ }^{(106)}$. Different plant fibers have been used as fillers; some have additional advantages such as being prebiotic, having antioxidant properties or increasing DF content. In this context, it is important to emphasize that the impact of sugar replacement and fiber addition on batter viscosity can be balanced by adjusting the water level in the formulations; in this regard, apple fiber has been used as bulk agent in sugar-replaced muffins ${ }^{(9 ; 107)}$.

\subsection{Fruit pomace fiber in brittle bakery products - cookies and biscuits}

Apart from energy content and nutritional value, the incorporation of fruit pomace as, for example, partial wheat flour replacement influences the development and the properties of a cookie or biscuit dough, the behavior during baking, and the properties of the final products. Types of pomace that were used in recent studies, the methods of initial pomace processing, and the respective replacement quantities are summarized in Table 2. 


\subsubsection{Influence on dough properties}

Farinograph experiments generally provide information on the moisture absorption capacity of the components of a formulation and on dough development time and dough stability, and they also provide a mixing tolerance index. Partial replacement of wheat flour or other formulation components by dried fruit by-products generally leads to increased moisture absorption. Ten percent wheat flour replacement by mango peel powder in a cookie formulation resulted, for example, in an increase of moisture absorption during dough kneading from $60 \%$ to $68 \%{ }^{(108)}$. A $10 \%$ flour replacement by grapefruit powder showed an even greater effect on moisture absorption by increasing it from $58.3 \%$ to $73.4 \%{ }^{(109)}$. Similar consequences were observed when different quantities of lemon or orange fiber ${ }^{(110)}$, apple pomace powder ${ }^{(111)}$, or orange pulp powder ${ }^{(112)}$ were used. The most plausible explanation for this behavior comes from the composition of the fruit powders, namely from its high content of pectin, being capable of binding high amounts of water ${ }^{(108)}$. Another reason that has been proposed is the formation of additional hydrogen bonds between the hydroxyl groups of the fruit pomace ${ }^{(113)}$. On the other hand, Mildner-Skudlarz et al. ${ }^{(114)}$ observed a reduced moisture absorption capacity of biscuit dough with white grape pomace and stated that several factors such as the chemical structure of the fiber, the association between fiber molecules, and fiber size and porosity influence the dough characteristics. The white grape pomace that was used in that study had high lignin content and therefore contributed differently to the dough matrix than high-pectin pomace powder.

The time necessary for dough development generally increases with fruit pomace addition because of gluten hydration prevention, either by interactions of DF with gluten 
proteins, or because of the competition for water that comes from the high moisture binding capacity of the fiber itself ${ }^{(110 ; 109 ; 111 ; 112)}$. For example, mango peel powder replacing $10 \%$ wheat flour in biscuits resulted in a dough development time of $5.8 \mathrm{~min}$, compared with $4.2 \mathrm{~min}$ for the corresponding control ${ }^{(108)}$. Dough stability measured by the Farinograph decreased, and dough development time increased when wheat flour was replaced by fruit pomace in different quantities $^{(110 ; 109 ; 114 ; 115)}$. This was explained by the dilution of the gluten proteins when DF is added, so that the proteins are not able to form a strong network ${ }^{(108)}$. The use of a surfactant may counteract this decrease, as was observed when $7.5 \%$ wheat flour of a biscuit formulation was replaced by dried pomegranate peel powder ${ }^{(115)}$. However, other authors attributed the increase in dough stability caused by the addition of fruit pomace ${ }^{(111 ; 112)}$ to enforced intermolecular interactions between DF, water and gluten.

In experiments with mixtures of wheat flour and pectin-enriched material (PEM) from apple pomace, it was observed that PEM interacts with the starch granules, and that starch pasting parameters increased with the addition of PEM. Differential scanning calorimetry experiments showed that PEM increased the endothermic starch gelatinization peak, indicating that more energy is required for the breakdown of the starch granules. Additionally, starch gelatinization temperature increased because of the high moisture absorption of PEM, so that less water remained available for starch gelatinization ${ }^{(116)}$.

\subsubsection{Influence on product characteristics}

In most studies on the application in biscuits or related products, dried pomace was employed as wheat flour replacement at levels of $2.5-50 \%$. The reduction of wheat flour in the dough and interactions of pomace components with wheat macromolecules result in a broad 
variation of product characteristics (e.g., volume, diameter, spread ratio, texture and color).

One important technological parameter is dough spreading during baking. Ajila et al. ${ }^{(108)}$ observed a significant decrease of cookie diameter at wheat flour replacement levels above $10 \%$, but no influence on the spread ratio. For citrus, grapefruit and apple pomace powder, the specific cookie volume and spread ratio decreased with increasing DF level (5, 10 and 15\%), which was explained by the reduced gluten content ${ }^{(110 ; 109 ; 111)}$. Extruded orange pulp powder had no significant influence on diameter up to $15 \%$ wheat flour replacement, whereas, compared to reference products, a $25 \%$ replacement reduced the diameter by $3.7 \%$, increased thickness by $17.9 \%$, and reduced the specific volume by $20.6 \%$. This was attributed to the high pectin content of the orange pulp powder ${ }^{(117)}$. The same behavior was observed for biscuits with pomegranate peel powder ${ }^{(115)}$. Contrasting results were reported for white grape pomace, where a $20 \%$ replacement of wheat flour increased cookie diameter by $4.4 \%$, decreased their thickness by $27.7 \%$, and the spread ratio by $44.3 \%$. White grape pomace in biscuit dough also increased moisture absorption, and the enhanced spread of the biscuits in the oven finally occurred before the products were becoming firm ${ }^{(114)}$.

Biscuit texture is most commonly measured as breaking strength in three-point snap experiments, and studies concerning the incorporation of fruit pomace show varying results. For example, the replacement of $20 \%$ wheat flour by the same amount of mango peel powder increased breaking strength from $8.8 \mathrm{~N}$ to $19.7 \mathrm{~N}$, which was explained by the higher moisture content of the dough with mango peel powder, causing an extensive gluten structure and therefore harder biscuits ${ }^{(108)}$. A similar observation was also reported by Larrea et al. ${ }^{(117)}$ for biscuits with orange pulp. Softer biscuits after addition of fruit pomace powder were reported 
for apple, where the fiber had a lower water content (5\%) compared to wheat flour (14\%) and thus influenced the protein and carbohydrate structure ${ }^{(118)}$. A similar behavior was observed for white grape pomace ${ }^{(114)}$.

Fruit pomace powder is often characterized by a yellow-brownish color (e.g., mango peel powder ${ }^{(108)}$, apple pomace powder ${ }^{(118)}$ or grape extract $\left.{ }^{(119)}\right)$. Consequently, replacement of wheat flour by fruit pomace usually affects the color of the respective biscuits.

Since the incorporated pomace powder derives from fruits, it is also associated with a particular flavor that might have an impact on the sensory characteristics of pomace-containing products. The addition of $10 \%$ mango peel powder produced acceptable biscuits with an improved taste and flavor that was attributed to the pleasantness of the underlying base material. Higher levels of mango peel powder (20\%) led to a slightly bitter taste because of the high polyphenol content ${ }^{(108)}$. In general, it was observed that a replacement of wheat flour up to $5 \%$ did not change the sensory scores significantly ${ }^{(120 ; 110 ; 111 ; 117 ; 112)}$. With addition of fruit pomace powder, the fruity taste and smell of the products increased, whereas much higher levels of replacement resulted in a more pronounced bitter and sour product character ${ }^{(121 ; 109 ;}$ ${ }^{114 ; 119)}$. In the studies of Srivastava et al. ${ }^{(115)}$ and Uysal et al. ${ }^{(122)}$, the overall sensory scores decreased with higher amounts of fiber incorporation.

\subsubsection{Application as fat replacement}

Besides its utilization as wheat flour replacement, it is also possible to replace other high energy ingredients such as sugar or fat by fruit pomace in brittle bakery products. For instance, PEM was used to substitute 10,20 or $30 \%$ of the shortening in a cookie formulation. Min et al. ${ }^{(116)}$ observed that PEM could not provide the same level of gas retention since cookies with 
PEM were reduced in diameter and height. Penetration force was reduced, and cookies exhibited a lower fracturability, which was explained by the higher availability of water in the PEM cookies. The change of cookie surface color was not significant. Özboy-Özbaş et al. ${ }^{(123)}$ used apricot kernel flour (AKF) and resistant starch (RS) for fat replacement in cookies. Spread ratios of cookies increased up to $20 \%$ replacement but then decreased when more than $30 \%$ shortening was replaced by the AKF/RS mixture. Cookie hardness decreased with replacement of more than $10 \%$. In color measurements, $b^{*}$ (an indicator for the yellow contribution to product color) decreased with increasing amounts of AKF and RS. Sensory scores of fat reduced cookies were not significantly different from the control and were all acceptable.

\subsubsection{Influence on content of dietary fiber and polyphenols}

Fruit pomace powder is usually characterized by a high DF content since it contains mainly cell wall compounds and seeds of pressed fruits, and the incorporation of such materials increases the DF content of the products. For example, an increase from $6.5-20.7 \%$ was observed when $20 \%$ of the wheat flour in biscuits was replaced with the same amount of mango peel powder ${ }^{(108)}$. Incorporation of $10 \%$ white grape pomace resulted in an $88 \%$ increase in total DF compared to control biscuits ${ }^{(114)}$.

Next to the DF enhancement, fruit pomace powder incorporation in brittle bakery products also contributes to a higher content of polyphenols, which remain associated with cell wall components after juice extraction. Twenty percent mango peel powder increased the polyphenol content in biscuits from 0.54-4.5 mg/g and the carotenoid content from 17-247 $\mu \mathrm{g} / \mathrm{g}^{(108)}$. Mildner-Szkudlarz et al. ${ }^{(114)}$ observed a six-fold increase in the antioxidant activity coming from the incorporation of $30 \%$ white grape pomace. Nevertheless, the high contents of 
polyphenols in fruit pomace usually decrease during thermal processing of powder and baking of biscuits ${ }^{(114 ; 119)}$.

\section{Application of fruit pomace in extruded products}

High-temperature, short-time extrusion is a common process for manufacturing snack products, usually with corn as the main ingredient, and frequently implemented so as to produce highly expanded products with distinct crispiness. Since fruit pomace powders are high in DF and polyphenols, their application in extruded products is a promising opportunity to fortify cereal snacks with health beneficial ingredients. Table 3 summarizes studies of extruded products with fruit pomace as ingredient. The high contents of SDF in most fruit pomace powders are responsible for changes in product characteristics such as water absorption index (WAI), water solubility index (WSI), texture, expansion, starch digestibility, and sensory properties. Additionally, the high shear and thermal stress may affect polyphenol content and antioxidant activity of the final product.

Incorporating fruit pomace in the extruder feed mixture lowers its starch content. The lower starch content in pomace-containing extrudates then leads to a lower water absorption (124-126), which affects starch gelatinization. The WAl is additionally influenced by the competition between starch and fruit pomace fiber for water, with the fiber showing the higher water binding capacity ${ }^{(124)}$. The high water affinity of fiber also explains why no significant differences were found in the WAI of corn flour extrudates and extrudates fortified with pineapple pomace ${ }^{(127)}$, or those fortified with other fruit pomace (orange peel, grape seeds, tomato pomace $\left.{ }^{(128)}\right)$. The WSI, on the other hand, describes the amount of soluble components in extrudates and points to the degradation of molecular compounds during extrusion (e.g., 
starch dextrinization). Altan et al. ${ }^{(124)}$ observed that the presence of pomace in cereal extrudates resulted in an increased WSI, whereas other studies observed a decrease of WSI with pomace addition. This could have been caused by reduced starch damage through the extrusion process ${ }^{(125)}$, or by the high content of DF coming with the pomace ${ }^{(127)}$.

With the use of pomace, the radial expansion of extrudates decreased and the bulk density increased, because of a lower extensibility, a lower gas holding capacity and reduced starch conversion in the base matrix ${ }^{(125 ; 129 ; 127)}$. Struck et al. ${ }^{(20)}$ noted that fiber particles cause rupture of cell walls before the gas bubbles fully expand (similar to the effects in bread, but in a system undergoing much more rapid expansion). For example, the addition of $28 \%$ apple pomace to corn flour resulted in $46-57 \%$ reduction of radial expansion but in insignificant changes in overall volumetric expansion, which was explained by the higher longitudinal expansion of apple pomace extrudates because of the alignment of fiber in the direction of extrusion $^{(130)}$.

Differences in expansion and bulk density directly influence the texture of pomace fortified cereal extrudates; a less porous structure with smaller cell sizes has been identified as responsible for decreased crispiness and increased brittleness ${ }^{(20)}$. Apple pomace in corn flour extrudates exhibited substantially higher crushing forces because, at pomace levels from 17$28 \%$, cell wall thickness was reduced by $32-44 \%$ and average cell wall diameter by $62 \%{ }^{(130)}$. Selani et al. ${ }^{(127)}$, however, found no difference in hardness between reference and pineapple pomace extrudates.

Since DF and starch interact with each other and compete for matrix water, pomace also influences in vitro starch digestibility of extrudates. In general, extrusion processing increases 
starch digestibility due to the high shear and thermal stresses during production, and the resulting starch gelatinization and dextrinization. The addition of grape pomace reduced in vitro starch digestibility in barley extrudates, presumably because of the lower susceptibility of starch to amylase degradation as the granules are entrapped within a viscous protein-fiberstarch network. Another explanation was the reduced starch gelatinization because of the competition for water ${ }^{(131)}$. Karkle et al. ${ }^{(125)}$ observed increased levels of resistant starch with increasing apple pomace level. It was also suggested that nonstarch polysaccharides such as pectin reduce the availability of starch for digestive enzymes and therefore reduce starch digestibility ${ }^{(13)}$.

The use of fruit pomace usually results in extrudates with a sweet and fruity taste ${ }^{(132 ;}$ ${ }^{133)}$. However, the application of more than $30 \%$ defatted blackcurrant seeds in cornmeal extrudates decreased overall sensory acceptability, whereas $10 \%$ produced the best results ${ }^{(134)}$. The method of processing fruit by-products was also shown to influence sensory characteristics, since extrudates with blackcurrant pomace from nonenzymatic treated press residues had higher sensory scores than extrudates with blackcurrant pomace that experienced conventional enzymatic treatment before pressing ${ }^{(126)}$.

As regards nutritional benefits, a number of studies showed that total phenolic content and antioxidant activity of fruit pomace decreased during extrusion processing ${ }^{(124 ; 133-136)}$. High screw speed resulted in reduced antioxidant activity during extrusion because of the destruction of antioxidants under high shear stress ${ }^{(124)}$. The influence of extrusion processing on individual phenolic compounds was also studied; flavonoids have been recognized as extremely thermolabile ${ }^{(134)}$, and anthocyanin retention was shown to depend on processing 
conditions such as barrel temperature, screw speed and feed moisture ${ }^{(137 ; 138)}$.

\section{Conclusions}

Enhancing the fiber content of bakery products has been an important theme of the cereal science literature, with fruit pomace from a great diversity of sources regularly studied in a range of bakery products, and offering additional benefits alongside increases in dietary fiber. The current review has surveyed the usage of fruit pomace in bread, cakes and muffins, cookies and biscuits, and extruded products. Prominent themes include the generally damaging effects of fiber on the aerated structure of cereal-based food products and ways to alleviate these, acceptable levels of fiber incorporation, and associated benefits in terms of flavor and increases in beneficial bioactive compounds. In general, fruit pomace can be included at significant levels in cereal-based products while maintaining consumer acceptability, enhancing the healthiness of the products and potentially conferring distinctiveness, while also offering valuable diversion of pomace from waste back into the food chain.

\section{Acknowledgement}

This review was conducted in the context of a research project that was approved during the 2nd SUSFOOD ERA-Net call (www.susfood-era.net). The funding, assured through the national partner organizations, is gratefully acknowledged: INIA in Spain, DEFRA in UK, and Federal Ministry of Education and Research via PTJ in Germany (grant 031B0004). 


\section{References}

1. Cauvain, S.P., Young, L.S. Technology of Breadmaking; Chapman and Hall: London, UK, 2008.

2. Figuerola, F., Hurtado, M.L., Estévez, A.M., Chiffelle, I., Asenjo, F. Fibre concentrates from apple pomace and citrus peel as potential fibre sources for food enrichment. Food Chemistry, 2005, 91, 395-401.

3. Rohm, H., Brennan, C., Turner, C., Günther, E., Campbell, G., Hernando, I., Struck, S., Kontogiorgos, V. Adding value to fruit processing waste: innovative ways to incorporate fibers from berry pomace in baked and extruded cereal-based foods-A SUSFOOD Project. Foods, 2015, 4, 690-697.

4. Sudha, M.L. Apple pomace (by-product of fruit juice industry) as a flour fortification strategy. In Flour and Breads and their Fortification in Health and Disease Prevention. Preedy, V.R.; Watson, R.R.; Patel, V.B., Eds. Elsevier: Amsterdam, 2011; 395-405.

5. Saura-Calixto, F. Antioxidant dietary fiber product: A new concept and a potential food ingredient. Journal of Agricultural and Food Chemistry, 1998, 46, 4303-4306.

6. Viebke, C., Al-Assaf, S., Phillips, G.O. Food hydrocolloids and health claims. Bioactive Carbohydrates and Dietary Fibre, 2014, 4, 101-114.

7. Lattimer, J.M., Haub, M.D. Effects of dietary fiber and its components on metabolic health. Nutrients, 2010, 2, 1266-1289.

8. Slavin, J. Fiber and prebiotics: Mechanisms and health benefits. Nutrients, 2013, 5, 14171435.

9. Struck, S., Gundel, L., Zahn, S., Rohm, H. Fiber enriched reduced sugar muffins made 
from iso-viscous batters. LWT - Food Science and Technology, 2016, 65, 32-38.

10. Grigelmo-Miguel, N., Martín-Belloso, O. Comparison of dietary fibre from by-products of processing fruits and greens and from cereals. LWT - Food Science and Technology, 1999, 32, 503-508.

11. Wang, L., Xu, H., Yuan, F., Pan, Q., Fan, R., Gao, Y. Physicochemical characterization of five types of citrus dietary fibers. Biocatalysis and Agricultural Biotechnology, 2015, 4, 250-258.

12. Martí, N., Saura, D., Fuentes, E., Lizama, V., García, E., Mico-Ballester, M.J., Lorente, J. Fiber from tangerine juice industry. Industrial Crops and Products, 2011, 33, 94-98.

13. Iora, S.R.F., Maciel, G.M., Zielinski, A.A.F., da Silva, M.V., Pontes, P.V.A., Haminiuk, C.W.I., Granato, D. Evaluation of the bioactive compounds and the antioxidant capacity of grape pomace. International Journal of Food Science and Technology, 2015, 50, 62-69.

14. Bravo, L., Saura-Calixto, F. Characterization of dietary fiber and the in vitro indigestible fraction of grape pomace. American Journal of Enology and Viticulture, 1998, 49, 135-141. 15. Yu, J., Ahmedna, M. Functional components of grape pomace: Their composition, biological properties and potential applications. International Journal of Food Science and Technology, 2013, 48, 221-237.

16. Milala, J., Kosmala, M., Sójka, M., Kołodziejczyk, K., Zbrzeåniak, M., Markowski, J. Plum pomaces as a potential source of dietary fibre: Composition and antioxidant properties. Journal of Food Science and Technology, 2013, 50, 1012-1017.

17. Matias, M.D.F.O., De Oliveira, E.L., Gertrudes, E., Dos Anjos Magalhães, M.M. Use of fibres obtained from the cashew (Anacardium ocidentale, $L$ ) and guava (Psidium guayava) fruits for enrichment of food products. Brazilian Archives of Biology and Technology, 2005, 48, 143- 
150.

18. Larrauri, J.A., Rupérez, P., Borroto, B., Saura-Calixto, F. Mango peels as a new tropical fibre: Preparation and characterization. LWT - Food Science and Technology, 1996, 29, 729-733.

19. Martín-Cabrejas, M.A., Esteban, R.M., López-Andreu, F.J., Waldron, K., Selvendran, R.R.

Dietary fiber content of pear and kiwi pomaces. Journal of Agricultural and Food Chemistry, $1995,43,662-666$.

20. Struck, S., Plaza, M., Turner, C., Rohm, H. Berry pomace - A review of processing and chemical analysis of its polyphenols. International Journal of Food Science and Technology, 2016, 51, 1305-1318.

21. Campbell, G.M. A history of aerated foods. Cereal Foods World, 2009, 54, 8-14.

22. Campbell, G., Ross, M., Motoi, L. Expansion capacity of bran-enriched doughs in different scales of laboratory mixers. In Bubbles in Food 2. Campbell, G. M.; Scanlon, M.G.; Pyle, D.L. Eds., Eagan Press: USA, 2008; 323-336.

23. Van der Kamp, J.W. New perspectives for dietary fibre research and development with novel research tools. Cereal Foods World, 2003, 48, 257-259.

24. Cauvain, S., Chamberlain, N., Collins, T., Davies, J. The distribution of dietary fibre and baking quality among mill fractions of CBP flour. FMBRA Report No, 1983, 5.

25. Collins, T.H. Making the best of brown bread. FMBRA Bulletin, 1983, 1, 3-13.

26. Collins, T., Young, L.S. Gluten fortification of brown flours used in the Chorleywood Bread Process. FMBRA Bulletin, 1986, 3, 95-101.

27. Collins, T.H., Fearn, T., Ford, W. The effect of gluten, fungal alpha-amylase and DATA ester in wholemeal bread made by CBP. FMBRA Bulletin, 1985, 5, 194-201. 
28. Dubois, D. The practical application of fiber materials in bread production. Bakers Digest, $1978,5,30-33$.

29. Galliard, T., Collins, A. Effects of oxidising improvers, an emulsifier, fat and mixer atmosphere on the performance of wholemeal flour in the chorleywood bread process. Journal of Cereal Science, 1988, 8, 139-146.

30. Lai, C., Davis, A., Hoseney, R. Production of whole wheat bread with good loaf volume. Cereal Chemistry, 1989, 66, 224-227.

31. Lai, C., Hoseney, R., Davis, A. Effects of wheat bran in breadmaking. Cereal Chemistry, $1989,66,217-219$.

32. Lai, C., Hoseney, R., Davis, A. Functional effects of shorts in breadmaking. Cereal Chemistry, 1989, 66, 220-223.

33. Pomeranz, Y. Fiber in breadmaking--a review of recent studies. Bakers Digest, 1977, 51. 34. Rogers, D., Hoseney, R. Problems associated with producing whole wheat bread. Cereal Foods World, 1982, 27, 451-454.

35. Shogren, M., Pomeranz, Y., Finney, K. Counteracting the deleterious effects of fiber in breadmaking. Cereal Chemistry, 1981, 58, 142-144.

36. Shetlar, M., Lyman, J. Effect of bran on bread baking. Cereal Chemistry, 1944, 21, 295304.

37. Dreese, P., Hoseney, R. Baking properties of the bran fraction from brewer's spent grains. Cereal Chemistry, 1982, 59, 89-91.

38. Galliard, T., Gallagher, D. The effects of wheat bran particle size and storage period on bran flavour and baking quality of bran/flour blends. Journal of Cereal Science, 1988, 8, 147- 
154.

39. Gan, Z., Ellis, P., Vaughan, J., Galliard, T. Some effects of non-endosperm components of wheat and of added gluten on wholemeal bread microstructure. Journal of Cereal Science, $1989,10,81-91$.

40. Pomeranz, Y., Shogren, M., Finney, K., Bechtel, D. Fiber in breadmaking--effects on functional properties. Cereal Chemistry, 1977, 54, 25-41.

41. Gan, Z., Galliard, T., Ellis, P., Angold, R., Vaughan, J. Effect of the outer bran layers on the loaf volume of wheat bread. Journal of Cereal Science, 1992, 15, 151-163.

42. Wootton, M., Shams-Ud-Din, M. The effects of aqueous extraction on the performance of wheat bran in bread. Journal of the Science of Food and Agriculture, 1986, 37, 387-390.

43. Zhang, D., Moore, W.R. Effect of wheat bran particle size on dough rheological properties. Journal of the Science of Food and Agriculture, 1997, 74, 490-496.

44. Sosulski, F., Wu, K. High-fiber breads containing field pea hulls, wheat, corn, and wild oat brans. Cereal Chemistry, 1988, 65, 186-191.

45. Chen, H., Rubenthaler, G., Leung, H., Baranowski, J. Chemical, physical, and baking properties of apple fiber compared with wheat and oat bran. Cereal Chemistry, 1988, 65, 244247.

46. D'appolonia, B., Youngs, V. Effect of bran and high-protein concentrate from oats on dough properties and bread quality. Cereal Chemistry, 1978, 55, 636-644.

47. Gan, Z., Ellis, P., Schofield, J. Gas cell stabilisation and gas retention in wheat bread dough. Journal of Cereal Science, 1995, 21, 215-230.

48. Zhang, D., Moore, W. Wheat bran particle size effects on bread baking performance and 
quality. Journal of the Science of Food and Agriculture, 1999, 79, 805-809.

49. Cadden, A.-M. Comparative effects of particle size reduction on physical structure and water binding properties of several plant fibers. Journal of Food Science, 1987, 52, 1595-1599. 50. Cadden, A.-M. Moisture sorption characteristics of several food fibers. Journal of Food Science, 1988, 53, 1150-1155.

51. Haseborg, E.t., Himmelstein, A. Quality problems with high-fiber breads solved by use of hemicellulase enzymes. Cereal Foods World, 1988, 33, 419-422.

52. Krishnan, P., Chang, K., Brown, G. Effect of commercial oat bran on the characteristics and composition of bread. Cereal Chemistry, 1987, 64, 55-58.

53. Laurikainen, T., Härkönen, H., Autio, K., Poutanen, K. Effects of enzymes in fibreenriched baking. Journal of the Science of Food and Agriculture, 1998, 76, 239-249.

54. Rasco, B., Borhan, M., Yegge, J., Lee, M., Siffring, K., Bruinsma, B. Evaluation of enzyme and chemically treated wheat bran ingredients in yeast-raised breads. Cereal Chemistry, 1991, 68, 295-299.

55. Campbell, G., Ross, M., Motoi, L. Bran in bread: effects of particle size and level of wheat and oat bran on mixing, proving and baking. In Bubbles in Food 2. Campbell, G. M.; Scanlon, M.G.; Pyle, D.L., Eds., Eagan Press: USA, 2008; 337-354.

56. Haridas Rao, P., Rao, H.M. Effect of incorporating wheat bran on the rheological characteristics and bread making quality of flour. Journal of Food Science and Technology, $1991,28,92-97$.

57. Sivam, A.S., Sun-Waterhouse, D., Quek, S., Perera, C.O. Properties of bread dough with added fiber polysaccharides and phenolic antioxidants: A review. Journal of Food Science, 2010, 
75, R163-R174.

58. Anil, M. Using of hazelnut testa as a source of dietary fiber in breadmaking. Journal of Food Engineering, 2007, 80, 61-67.

59. Chang, R.C., Li, C.Y., Shiau, S.Y. Physico-chemical and sensory properties of bread enriched with lemon pomace fiber. Czech Journal of Food Sciences, 2015, 33, 180-185.

60. Katina, K. High-fibre baking, Bread Making: Improving Quality, 2003; 487-499.

61. Lorenz, K. Triticale bran in fiber breads. Bakers Digest, 1976, 50, 27-30.

62. Masoodi, F.A., Chauhan, G.S. Use of apple pomace as a source of dietary fiber in wheat bread. Journal of Food Processing and Preservation, 1998, 22, 255-263.

63. O'Shea, N., Doran, L., Auty, M., Arendt, E., Gallagher, E. The rheology, microstructure and sensory characteristics of a gluten-free bread formulation enhanced with orange pomace. Food and Function, 2013, 4, 1856-1863.

64. O'Shea, N., Rößle, C., Arendt, E., Gallagher, E. Modelling the effects of orange pomace using response surface design for gluten-free bread baking. Food Chemistry, 2015, 166, 223 230.

65. Prentice, N., D'appolonia, B. High-fiber bread containing brewer's spent grain. Cereal Chemistry, 1977, 54, 1084-1095.

66. Rosell, C.M., Santos, E., Collar, C. Mixing properties of fibre-enriched wheat bread doughs: A response surface methodology study. European Food Research and Technology, 2006, 223, 333-340.

67. Walker, R., Tseng, A., Cavender, G., Ross, A., Zhao, Y. Physicochemical, nutritional, and sensory qualities of wine grape pomace fortified baked goods. Journal of Food Science, 2014, 
79, S1811-S1822.

68. Başman, A., Köksel, H. Properties and composition of Turkish flat bread (Bazlama) supplemented with barley flour and wheat bran. Cereal Chemistry, 1999, 76, 506-511.

69. Waghmare, A.G., Arya, S.S. Use of fruit by-products in the preparation of hypoglycemic thepla: indian unleavened vegetable flat bread. Journal of Food Processing and Preservation, 2014, 38, 1198-1206.

70. Barnes, P.J., Lowy, G.D.A. The effect on baking quality of interaction between milling fractions during the storage of wholemeal flour. Journal of Cereal Science, 1986, 4, 225-232. 71. Campbell, G., Koh, K.C., Keung, Y.M., Morgenstern, M. Effect of wheat bran particle size on aeration of bread dough during mixing. In Bubbles in Food 2. Campbell, G.M.; Scanlon, M.G.; Pyle, D.L. Eds., Eagan Press: USA, 2008; 355-368.

72. De Kock, S., Taylor, J., Taylor, J.R.N. Effect of heat treatment and particle size of different brans on loaf volume of brown bread. LWT - Food Science and Technology, 1999, 32, 349-356.

73. Moder, G., Finney, K., Bruinsma, B., Ponte, J., Bolte, L. Bread-making potential of straight-grade and whole-wheat flours of Triumph and Eagle-Plainsman $V$ hard red winter wheats. Cereal Chemistry, 1984, 61, 269-273.

74. Nelles, E.M., Randall, P.G., Taylor, J.R.N. Improvement of brown bread quality by prehydration treatment and cultivar selection of bran. Cereal Chemistry, 1998, 75, 536-540. 75. Doehlert, D.C., Moore, W.R. Composition of oat bran and flour prepared by three different mechanisms of dry milling. Cereal Chemistry, 1997, 74, 403-406.

76. Rocha Parra, A.F., Ribotta, P.D., Ferrero, C. Apple pomace in gluten-free formulations: effect on rheology and product quality. International Journal of Food Science \& Technology, 
$2015,50,682-690$.

77. Anonymous. Zusammensetzung von Brot und anderen Backwaren. 1999.

78. Bielig, H., Fanghaenel, K.D.I., Kuettner, D., Viehweger, T., Strauss, J.D.I., Popp, V. Process for the production of bakery and patisserie products. 1984 .

79. Holzmüller, J. Verwendung von Aronia. 2012.

80. John, T. Verfahren zur Herstellung von funktionellen Lebensmitteln. 2003.

81. Pateras, I.M.C., Howells, K.F., Rosenthal, A.J. Hot-stage microscopy of cake batter bubbles during simulated baking: sucrose replacement by polydextrose. Journal of Food Science, 1994, 59, 168-170.

82. Cauvain, S.P., Young, L.S. Baked Products: Science, Technology and Practice; Blackwell Publishing: Oxford, UK, 2007; 228.

83. Foschia, M., Peressini, D., Sensidoni, A., Brennan, C.S. The effects of dietary fibre addition on the quality of common cereal products. Journal of Cereal Science, $\mathbf{2 0 1 3}, \mathbf{5 8 , 2 1 6 -}$ 227.

84. Grigor, J.M., Brennan, C.S., Hutchings, S.C., Rowlands, D.S. The sensory acceptance of fibre-enriched cereal foods: A meta-analysis. International Journal of Food Science and Technology, 2016, 51, 3-13.

85. Wang, H.J., Thomas, R.L. Direct use of apple pomace in bakery products. Journal of Food Science, $1989,54,618-620$.

86. Masoodi, F.A., Sharma, B., Chauhan, G.S. Use of apple pomace as a source of dietary fiber in cakes. Plant Foods for Human Nutrition, 2002, 57, 121-128.

87. Rupasinghe, H.P.V., Wang, L., Huber, G.M., Pitts, N.L. Effect of baking on dietary fibre 
and phenolics of muffins incorporated with apple skin powder. Food Chemistry, 2008, 107, $1217-1224$.

88. Madhugiri, L.S., Krishna, R.L., Vallikannan, B. An improved process for the preparation of fibre rich cake. 2009.

89. Sudha, M.L., Indumathi, K., Sumanth, M.S., Rajarathnam, S., Shashirekha, M.N. Mango pulp fibre waste: characterization and utilization as a bakery product ingredient. Journal of Food Measurement and Characterization, 2015, 9, 382-388.

90. Romero-Lopez, M.R., Osorio-Diaz, P., Bello-Perez, L.A., Tovar, J., Bernardino-Nicanor, A. Fiber concentrate from orange (Citrus sinensis L.) bagase: Characterization and application as bakery product ingredient. International Journal of Molecular Sciences, 2011, 12, 2174-2186. 91. Mildner-Szkudlarz, S., Siger, A., Szwengiel, A., Bajerska, J. Natural compounds from grape by-products enhance nutritive value and reduce formation of $\mathrm{CML}$ in model muffins. Food Chemistry, 2015, 172, 78-85.

92. Rodríguez-García, J., Sahi, S., Hernando, I. Functionality of lipase and emulsifiers in lowfat cakes with inulin. LWT - Food Science and Technology, 2014, 58, 173-182.

93. Lai, H.M., Lin, T.C. Bakery Products: Science and Technology. In Bakery Products: Science and Technology. Hui, Y.H., Ed. Blackwell Publishing, Oxford, UK, 2007; 3-68.

94. Rodríguez-García, J., Salvador, A., Hernando, I. Replacing fat and sugar with inulin in cakes: bubble size distribution, physical and sensory properties. Food and Bioprocess Technology, 2014, 7, 964-974.

95. Khalil, A.H. The influence of carbohydrate-based fat replacers with and without emulsifiers on the quality characteristics of lowfat cake. Plant Foods for Human Nutrition, 1998, 
52, 299-313.

96. Matsakidou, A., Blekas, G., Paraskevopoulou, A. Aroma and physical characteristics of cakes prepared by replacing margarine with extra virgin olive oil. LWT - Food Science and Technology, 2010, 43, 949-957.

97. Bennion, E., Bamford, G. Cake making processes. In The Technology of Cake Making. Bent, A.J.E., Ed. Blake Academic, London, UK, 1997; 252-270.

98. Sikorski, Z.E., Sikorska-Wiśniewska, G. The role of lipids in food quality. In Improving the Fat Content of Foods. Williams, C.; Buttriss, J., Eds. Woodhead Publishing: Cambridge, UK, 2006; 213-235.

99. Barker, P., Cauvain, S. Fat and calorie-modified bakery products. International Food Ingredients, 1994, 1, 19-24.

100. Zahn, S., Pepke, F., Rohm, H. Effect of inulin as a fat replacer on texture and sensory properties of muffins. International Journal of Food Science and Technology, 2010, 45, 25312537.

101. Grigelmo-Miguel, N., Carreras-Boladeras, E., Martín-Belloso, O. Influence of the addition of peach dietary fiber in composition, physical properties and acceptability of reduced-fat muffins. Food Science and Technology International, 2001, 7, 425-431.

102. Al-Sayed, H.M.A., Ahmed, A.R. Utilization of watermelon rinds and sharlyn melon peels as a natural source of dietary fiber and antioxidants in cake. Annals of Agricultural Sciences, 2013, 58, 83-95.

103. Kocer, D., Hicsasmaz, Z., Bayindirli, A., Katnas, S. Bubble and pore formation of the highratio cake formulation with polydextrose as a sugar- and fat-replacer. Journal of Food 
Engineering, 2007, 78, 953-964.

104. Baker, B., Davis, E., Gordon, J. The influence of sugar and emulsifier type during microwave and conventional heating of a lean formula cake batter. Cereal Chemistry, 1990, 67, 451-457.

105. Hicsasmaz, Z., Yazgan, Y., Bozoglu, F., Katnas, Z. Effect of polydextrose-substitution on the cell structure of the high-ratio cake system. LWT - Food Science and Technology, 2003, 36, 441-450.

106. Struck, S., Jaros, D., Brennan, C.S., Rohm, H. Sugar replacement in sweetened bakery goods. International Journal of Food Science \& Technology, 2014, 49, 1963-1976.

107. Zahn, S., Forker, A., Krügel, L., Rohm, H. Combined use of rebaudioside A and fibres for partial sucrose replacement in muffins. LWT - Food Science and Technology, 2013, 50, 695-701. 108. Ajila, C.M., Leelavathi, K., Prasada Rao, U.J.S. Improvement of dietary fiber content and antioxidant properties in soft dough biscuits with the incorporation of mango peel powder. Journal of Cereal Science, 2008, 48, 319-326.

109. Kohajdová, Z., Karovičová, J., Jurasová, M. Influence of grapefruit dietary fibre rich powder on the rheological characteristics of wheat flour dough and on biscuit quality. Acta Alimentaria, 2013, 42, 91-101.

110. Kohajdová, Z., Karovičacute, ová, J., Jurasová, M., Kukurová, K. Application of citrus dietary fibre preparations in biscuit production. Journal of Food and Nutrition Research, 2011, $50,182-190$.

111. Kohajdová, Z., Karovičová, J., Magala, M., Kuchtová, V. Effect of apple pomace powder addition on farinographic properties of wheat dough and biscuits quality. Chemical Papers, 
2014, 68, 1059-1065.

112. Nassar, A., AbdEl-Hamied, A., El-Naggar, E. Effect of citrus by-products flour incorporation on chemical, rheological and organolepic characteristics of biscuits. World Journal of Agricultural Sciences, 2008, 4, 612-616.

113. Rosell, C.M., Rojas, J.A., Benedito de Barber, C. Influence of hydrocolloids on dough rheology and bread quality. Food Hydrocolloids, 2001, 15, 75-81.

114. Mildner-Szkudlarz, S., Bajerska, J., Zawirska-Wojtasiak, R., Górecka, D. White grape pomace as a source of dietary fibre and polyphenols and its effect on physical and nutraceutical characteristics of wheat biscuits. Journal of the Science of Food and Agriculture, 2013, 93, 389395.

115. Srivastava, P., Indrani, D., Singh, R.P. Effect of dried pomegranate (Punica granatum) peel powder (DPPP) on textural, organoleptic and nutritional characteristics of biscuits. International Journal of Food Sciences and Nutrition, 2014, 65, 827-833.

116. Min, B., Bae, I.Y., Lee, H.G., Yoo, S.H., Lee, S. Utilization of pectin-enriched materials from apple pomace as a fat replacer in a model food system. Bioresource Technology, 2010, $101,5414-5418$.

117. Larrea, M.A., Chang, Y.K., Martínez Bustos, F. Effect of some operational extrusion parameters on the constituents of orange pulp. Food Chemistry, 2005, 89, 301-308.

118. Jung, J., Cavender, G., Zhao, Y. Impingement drying for preparing dried apple pomace flour and its fortification in bakery and meat products. Journal of Food Science and Technology, 2015, 52, 5568-5578.

119. Pasqualone, A., Bianco, A.M., Paradiso, V.M., Summo, C., Gambacorta, G., Caponio, F. 
Physico-chemical, sensory and volatile profiles of biscuits enriched with grape marc extract. Food Research International, 2014, 65, 385-393.

120. Carson, K.J., Collins, J.L., Penfield, M.P. Unrefined, dried apple pomace as a potential food ingredient. Journal of Food Science, 1994, 59, 1213-1215.

121. Górecka, D., Pachołek, B., Dziedzic, K., Górecka, M. Raspberry pomace as a potential fiber source for cookies enrichment. ACTA Scientiarum Polonorum Technologia Alimentaria, 2010, 9, 451-461.

122. Uysal, H., Bilgiçli, N., Elgün, A., Ibanoğlu, Ş., Herken, E.N., Kürşat Demir, M. Effect of dietary fibre and xylanase enzyme addition on the selected properties of wire-cut cookies. Journal of Food Engineering, 2007, 78, 1074-1078.

123. Özboy-Özbaş, O., Seker, I.T., Gökbulut, I. Effects of resistant starch, apricot kernel flour, and fiber-rich fruit powders on low-fat cookie quality. Food Science and Biotechnology, 2010, 19, 979-986.

124. Altan, A., McCarthy, K.L., Maskan, M. Effect of extrusion process on antioxidant activity, total phenolics and $\beta$-glucan content of extrudates developed from barley-fruit and vegetable by-products. International Journal of Food Science \& Technology, 2009, 44, 1263-1271.

125. Karkle, E.L., Keller, L., Dogan, H., Alavi, S. Matrix transformation in fiber-added extruded products: Impact of different hydration regimens on texture, microstructure and digestibility. Journal of Food Engineering, 2012, 108, 171-182.

126. Mäkilä, L., Laaksonen, O., Diaz, J.M.R., Vahvaselkä, M., Myllymäki, O., Lehtomäki, I., Laakso, S., Jahreis, G., Jouppila, K., Larmo, P. Exploiting blackcurrant juice press residue in extruded snacks. LWT-Food Science and Technology, 2014, 57, 618-627. 
127. Selani, M.M., Brazaca, S.G.C., dos Santos Dias, C.T., Ratnayake, W.S., Flores, R.A., Bianchini, A. Characterisation and potential application of pineapple pomace in an extruded product for fibre enhancement. Food Chemistry, 2014, 163, 23-30.

128. Yağcl, S., Göğüş, F. Response surface methodology for evaluation of physical and functional properties of extruded snack foods developed from food-by-products. Journal of Food Engineering, 2008, 86, 122-132.

129. Paraman, I., Sharif, M.K., Supriyadi, S., Rizvi, S.S. Agro-food industry byproducts into value-added extruded foods. Food and Bioproducts Processing, 2015, 96, 78-85.

130. Karkle, E.L., Alavi, S., Dogan, H. Cellular architecture and its relationship with mechanical properties in expanded extrudates containing apple pomace. Food Research International, $2012,46,10-21$.

131. Altan, A., McCarthy, K., Maskan, M. Effect of extrusion cooking on functional properties and in vitro starch digestibility of barley-based extrudates from fruit and vegetable by-products. Journal of Food Science, 2009, 74, E77-E86.

132. Altan, A., McCarthy, K.L., Maskan, M. Twin-screw extrusion of barley-grape pomace blends: Extrudate characteristics and determination of optimum processing conditions. Journal of Food Engineering, 2008, 89, 24-32.

133. Drożdż, W., Tomaszewska-Ciosk, E., Zdybel, E., Boruczkowska, H., Boruczkowski, T., Regiec, P. Effect of apple and rosehip pomaces on colour, total phenolics and antioxidant activity of corn extruded snacks. Polish Journal of Chemical Technology, 2014, 16, 7-11. 134. Gumul, D., Ziobro, R., ZIĘBA, T., Roj, E. The influence of addition of defatted blackcurrant seeds on pro-health constituents and texture of cereal extrudates. Journal of Food Quality, 
2011, 34, 395-402.

135. Khanal, R., Howard, L., Brownmiller, C., Prior, R. Influence of extrusion processing on procyanidin composition and total anthocyanin contents of blueberry pomace. Journal of Food Science, 2009, 74, H52-H58.

136. Khanal, R., Howard, L., Prior, R. Procyanidin content of grape seed and pomace, and total anthocyanin content of grape pomace as affected by extrusion processing. Journal of Food Science, 2009, 74, H174-H182.

137. Hirth, M., Leiter, A., Beck, S.M., Schuchmann, H.P. Effect of extrusion cooking process parameters on the retention of bilberry anthocyanins in starch based food. Journal of Food Engineering, 2014, 125, 139-146.

138. White, B.L., Howard, L.R., Prior, R.L. Polyphenolic composition and antioxidant capacity of extruded cranberry pomace. Journal of Agricultural and Food Chemistry, 2010, 58, 40374042. 
Table 1

Use of fruit pomace as ingredient in soft bakery products

\begin{tabular}{|c|c|c|c|}
\hline Application & $\begin{array}{l}\text { Fruit } \\
\text { pomace }\end{array}$ & Amount of pomace used in & Reference \\
\hline \multirow{8}{*}{$\begin{array}{l}\text { Wheat flour } \\
\text { Replacement }\end{array}$} & \multirow[t]{3}{*}{ Apple } & 5,10 or $15 \%$ apple pomace in cakes & $(62)$ \\
\hline & & up to $32 \%$ apple skin powder in muffins & $(87)$ \\
\hline & & $50 \%$ powered apple pomace in muffins & $(85)$ \\
\hline & \multirow[t]{2}{*}{ Grape } & $\begin{array}{l}10,15 \text { or } 20 \% \text { wine grape pomace in } \\
\text { muffins }\end{array}$ & $(67)$ \\
\hline & & $\begin{array}{l}10,20 \text { or } 30 \% \text { grape by-product in } \\
\text { muffins }\end{array}$ & \\
\hline & Mango & $\begin{array}{l}20,40 \text { or } 60 \% \text { mango pulp fibre waste } \\
\text { in muffins } \\
10,20 \text { or } 30 \% \text { dry mango pulp fibre } \\
\text { waste in muffins }\end{array}$ & (89) \\
\hline & Melon & $\begin{array}{l}2.5,5 \text { or } 7.5 \% \text { melon skin and rinds } \\
\text { powders in cakes }\end{array}$ & $(102)$ \\
\hline & Orange & $\begin{array}{l}10 \text { or } 15 \% \text { dietary fibre-rich orange } \\
\text { bagasse in muffins }\end{array}$ & (90) \\
\hline \multirow[t]{2}{*}{$\begin{array}{l}\text { Fat } \\
\text { replacement }\end{array}$} & Melon & $\begin{array}{l}5,10 \text { or } 15 \% \text { melon skin and rinds } \\
\text { powders in cakes }\end{array}$ & $(102)$ \\
\hline & Peach & $\begin{array}{l}2,3,4,5 \text { or } 10 \% \text { peach dietary fibre in } \\
\text { muffins }\end{array}$ & (101) \\
\hline \multirow[t]{2}{*}{$\begin{array}{l}\text { Sugar } \\
\text { replacement }\end{array}$} & Apple & $\begin{array}{l}30 \% \text { fibre, water and rebaudioside } \mathrm{A} \text { in } \\
\text { muffins }\end{array}$ & $(107)$ \\
\hline & & $\begin{array}{l}30,60 \text { or } 100 \% \text { fibre, water and } \\
\text { rebaudioside A in muffins }\end{array}$ & (9) \\
\hline
\end{tabular}


Table 2

Use of fruit pomace as ingredient in brittle bakery products

Type of Pomace processing prior to use pomace

Pomace

Reference

Mango peels Washing with water, drying at $50^{\circ} \mathrm{C}$ in cross-

application

Replacement of

flow drier for $18 \mathrm{~h}$ to $10 \%$ moisture, powdering $5,7.5,10,15$ or with a hammer mill, sieving through $150 \mu \mathrm{m}$ $20 \%$ wheat flour sieve.

in biscuits

Apple Grinding in meat grinder, drying on drum dryer pomace at $162.8^{\circ} \mathrm{C}$ surface temperature, further drying in a cabinet dehydrator at $55^{\circ} \mathrm{C}$ for $3 \mathrm{~h}$, subsequent milling.

Replacement of

Freezing at $-24{ }^{\circ} \mathrm{C}$. Drying: (a) Convective forced air drying at $40^{\circ} \mathrm{C}$; (b) Impingement 30,40 or $50 \%$ oatmeal in cookies drying at $110^{\circ} \mathrm{C}$, or (c) Freeze drying at $-55^{\circ} \mathrm{C}$ flour in cookies Replacement of and $17.33 \mathrm{~Pa}$. Grinding with laboratory mill fitted with a $0.5 \mathrm{~mm}$ screen, vacuum packaging, frozen storage $\left(-24^{\circ} \mathrm{C}\right)$.

Convective drying at $40{ }^{\circ} \mathrm{C}$ for $8 \mathrm{~h}$, milling in Replacement of grinder mill, sieving to obtain a particle size of 5,10 or $15 \%$ 160-270 $\mu \mathrm{m}$. wheat flour in biscuits

Drying, grinding to pass through a 50 mesh Replacement of sieve. Mixing with distilled water for 1 h, 3 min 10, 20 or $30 \%$ homogenization with an ultrasonic shortening with homogenizer, autoclaving at $121^{\circ} \mathrm{C}$ for $10 \mathrm{~min}$. PEM gels in Treatment with Viscozyme at $40{ }^{\circ} \mathrm{C}$ for $1 \mathrm{~h}, \quad$ cookies boiling for $5 \mathrm{~min}$, filtering and freeze drying to obtain the further used pectin-enriched material (PEM).

Drying in a double-drum drier at $162.8^{\circ} \mathrm{C}, 80$ psi, $2.5 \mathrm{rpm}$, or freeze drying. Grinding to $<20$ Replacement of $40 \%$ wheat flour mesh with Wiley Mill. in the crust, and of $40 \%$ oats in the filling of Oriental moon cookies 
Citrus peels Chopping, drying at $40{ }^{\circ} \mathrm{C}$ for $14 \mathrm{~h}$, milling in grinder mill, sieving to obtain particle size of 160-270 $\mu \mathrm{m}$.

Grapefruit Chopping, drying at $40{ }^{\circ} \mathrm{C}$ for $14 \mathrm{~h}$, milling in peels grinder mill, sieving to obtain particle size of 160-270 $\mu \mathrm{m}$.

Orange peels Drying in forced-air convection oven at $80{ }^{\circ} \mathrm{C}$ for $12 \mathrm{~h}$ to $9 \%$ moisture, milling to particle size $<4.2 \mathrm{~mm}$, extrusion at barrel temperatures of $83,100,125,150$ or $167^{\circ} \mathrm{C}$ with moisture content $22,25,30$ or $38 \%$, and screw speed $126,140,160,180$ or $194 \mathrm{rpm}$.

Washing, pressing in helical press, drying at 50 Replacement of ${ }^{\circ} \mathrm{C}$ for $24 \mathrm{~h}$, milling in grinder mill to particle size $<0.2 \mathrm{~mm}$.

Guave Frozen storage at $-18^{\circ} \mathrm{C}$, drying at $55^{\circ} \mathrm{C}$ until bagasse constant weight.

White grape Freeze drying to $2-4 \%$ moisture, sieving to pomace separate skins from seeds, milling to particle size $<150 \mu \mathrm{m}$.

Grape marc Freeze drying, crushing, homogenization, extract mixing with ethanol and citric acid, (GME) centrifugation, concentration of supernatant in vacuum evaporator.

Raspberry Pomace obtained in dry form, used in crumbled pomace or non-crumbled form.

Apricot Washing of kernels, air drying at $30{ }^{\circ} \mathrm{C}$ for 2 kernel flour wks, cracking, soaking in warm water for $1 \mathrm{~h}$, drying for $2 \mathrm{~h}$, grinding in coffee grinder.

Replacement of

5,10 or $15 \%$

wheat flour in

biscuits

Replacement of

5,10 or $15 \%$ wheat flour in biscuits

Replacement of 5,15 or $25 \%$ wheat flour in sugar-snap cookies

5,15 or $25 \%$ wheat flour in biscuits

Incorporation of

5,10 or $15 \%$ in cookies

Replacement of 10,20 or $30 \%$ wheat flour in wheat biscuits

Replacement of $125 \mathrm{~mL}$ water by $225 \mathrm{~mL} \mathrm{GME}$ and $50 \mathrm{~mL}$ water 25 or $50 \%$ wheat flour in cookies Replacement of $10,20,30,40$ or $50 \%$ shortening in low-fat cookies Pomegranate Washing, cutting, drying at $40{ }^{\circ} \mathrm{C}$ for $5-6 \mathrm{~h}, \quad$ Replacement of 
peel powder powdering in blender, sieving through $250 \mu \mathrm{m} \quad 2.5,5,7.5$ or $10 \%$ sieve.

wheat flour in

biscuits 
Table 3

Use of fruit pomace as ingredient in extruded products

Type of pomace Pomace application Refence

Grape pomace $\quad 0,2,6,10$ or $12.7 \%$ in barley flour

$(127,131,132)$

Apple pomace $\quad 0,10,15$ or $20 \%$ in corn grits

Rosehip pomace

Defatted black $\quad 0,10,30$ or $50 \%$ in cornmeal

currant seeds

Black currant pomace $27-28 \%$ black currant pomace, $38-39 \%$

(126)

mixture of barley flour, oat flour and oat bran, and $14-15 \%$ potato starch

Bilberry extract

$2 \%$ in maize

(137)

Apple pomace

$0,17,22$ or $28 \%$ in corn flour

$(125,130)$

$22-28 \%$ in pregelatinized starch and other ingredients

Blueberry pomace $\quad 30 \%$ in white sorghum

Pineapple pomace $\quad 0,10.5$ or $21 \%$ in corn flour

Cranberry pomace

30,40 or $50 \%$ in corn starch

Orange peel, grape $\quad 3-7 \%$ in rice grits, durum clear flour, defatted (128) seeds, tomato pomace hazelnut flour 